\title{
Association of weaning preparedness with extubation outcome of mechanically ventilated patients in medical intensive care units: a retrospective analysis
}

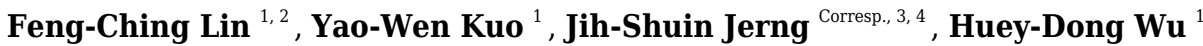 \\ ${ }^{1}$ Department of Integrated Diagnostics \& Therapeutics, National Taiwan University Hospital, Taipei, Taiwan \\ 2 Department of Nursing, Cardinal Tien Junior College of Healthcare and Management, New Taipei City, Taiwan \\ 3 Department of Internal Medicine, National Taiwan University Hospital, Taipei, Taiwan \\ ${ }^{4}$ Center for Quality Management, National Taiwan University Hospital, Taipei, Taiwan \\ Corresponding Author: Jih-Shuin Jerng \\ Email address: jsjerng@ntu.edu.tw
}

Background: Assessment of preparedness of weaning has been recommended before extubation for mechanically ventilated patients. We aimed to understand the association of a structured assessment of weaning preparedness with successful liberation.

Methods: We retrospectively investigated patients with acute respiratory failure who experienced an extubation trial at the medical intensive care units of a medical center, and compared the demographic and clinical characteristics between those patients with successful and failed extubation. A composite score to assess the preparedness of weaning, the WEANS NOW score, was generated consisting of eight components, including Weaning parameters, Endotracheal tube, Arterial blood gas analysis, Nutrition, Secretions, Neuromuscular-affecting agents, Obstructive airway problems, and Wakefulness. The prognostic ability of the WEANSNOW score for extubation was then analyzed.

Results: Of the 205 patients included, 138 (67.3\%) patients had successful extubation. Compared with the failure group, the success group had a significantly shorter duration of MV before the weaning attempt (11.2 \pm 11.6 vs. $31.7 \pm 26.2$ days, $p<0.001)$, more with congestive heart failure $(42.0 \%$ vs. $25.4 \%$, $p=0.020)$, and had different distribution of the types of acute respiratory failure $(p=0.037)$. The failure group also had a higher WEANS NOW score (1.22 \pm 0.85 vs.0.51 $\pm 0.71, p<0.001)$ and worse Rapid Shallow Breathing Index (93.9 \pm 63.8 vs. 56.3 $\pm 35.1, p<0.001)$. Multivariate logistic regression analysis showed that a WEANS NOW Score $=1$ or higher $(\mathrm{OR}=2.880,95 \% \mathrm{Cl}=1.291-6.426, \mathrm{p}=0.010)$ and intubation duration $>21$ days $(\mathrm{OR}=7.752,95 \% \mathrm{Cl}=3.560-16.879, \mathrm{p}<0.001)$ were independently associated with an increased probability of extubation failure.

Conclusion: Assessing the pre-extubation status of intubated patients in a checklist-based approach using the WEANS NOW score might provide valuable insights into extubation failure in patients in a medical ICU for acute respiratory failure. Further prospective studies are warranted to elucidate the practice of assessing weaning preparedness. 


\section{Association of weaning preparedness with extubation outcome of}

2 mechanically ventilated patients in medical intensive care units: a

3 retrospective analysis

4

5 Feng-Ching Lin ${ }^{1,4}$, Yao-Wen Kuo ${ }^{1}$, Jih-Shuin Jerng ${ }^{2,3}$, Huey-Dong Wu ${ }^{1}$

6

$7 \quad{ }^{1}$ Department of Integrated Diagnostics \& Therapeutics, National Taiwan University Hospital,

8 Taipei, Taiwan

9 2Department of Internal Medicine, National Taiwan University Hospital, Taipei, Taiwan

$10{ }^{3}$ Center for Quality Management, National Taiwan University Hospital, Taipei, Taiwan

$11{ }^{4}$ Department of Nursing, Cardinal Tien Junior College of Healthcare and Management, New

12 Taipei City, Taiwan

14 Corresponding Author:

15 Jih-Shuin Jerng

16 No. 7 Zhongshan South Road, Taipei 10002, Taiwan

17 Email address: jsjerng@ntu.edu.tw 


\section{Abstract}

19 Background: Assessment of preparedness of weaning has been recommended before extubation

20 for mechanically ventilated patients. We aimed to understand the association of a structured

21 assessment of weaning preparedness with successful liberation.

22 Methods: We retrospectively investigated patients with acute respiratory failure who experienced an extubation trial at the medical intensive care units of a medical center, and compared the demographic and clinical characteristics between those patients with successful and failed extubation. A composite score to assess the preparedness of weaning, the WEANS NOW score, was generated consisting of eight components, including $W$ eaning parameters,

27 Endotracheal tube, Arterial blood gas analysis, Nutrition, Secretions, Neuromuscular-affecting 28 agents, Obstructive airway problems, and $W$ akefulness. The prognostic ability of the 29 WEANSNOW score for extubation was then analyzed.

30 Results: Of the 205 patients included, 138 (67.3\%) patients had successful extubation.

31 Compared with the failure group, the success group had a significantly shorter duration of MV

32 before the weaning attempt $(11.2 \pm 11.6$ vs. $31.7 \pm 26.2$ days, $\mathrm{p}<0.001)$, more with congestive heart 33 failure ( $42.0 \%$ vs. $25.4 \%, \mathrm{p}=0.020)$, and had different distribution of the types of acute

34 respiratory failure $(\mathrm{p}=0.037)$. The failure group also had a higher WEANS NOW score $(1.22 \pm$ 350.85 vs. $0.51 \pm 0.71, \mathrm{p}<0.001)$ and worse Rapid Shallow Breathing Index (93.9 \pm 63.8 vs. $56.3 \pm$ $3635.1, \mathrm{p}<0.001)$. Multivariate logistic regression analysis showed that a WEANS NOW Score $=1$ 37 or higher $(\mathrm{OR}=2.880,95 \% \mathrm{CI}=1.291-6.426, \mathrm{p}=0.010)$ and intubation duration $>21$ days $38(\mathrm{OR}=7.752,95 \% \mathrm{CI}=3.560-16.879, \mathrm{p}<0.001)$ were independently associated with an increased 39 probability of extubation failure. 
40 Conclusion: Assessing the pre-extubation status of intubated patients in a checklist-based

41 approach using the WEANS NOW score might provide valuable insights into extubation failure

42 in patients in a medical ICU for acute respiratory failure. Further prospective studies are warranted

43 to elucidate the practice of assessing weaning preparedness.

\section{Introduction}

47 Weaning from mechanical ventilation (MV) is an essential task in the care of patients with acute 48 respiratory failure. Despite advances in assessing the feasibility of extubation, the rate of 49 reintubation remains high at $10 \%$ to $19 \%$, with a high mortality rate in those who fail extubation of $25 \%$ to $50 \%$ (Thille, Cortés-Puch et al. 2013). The failure rate at the first attempt to wean can be as high as 50\% (Peñuelas, Frutos-Vivar et al. 2011) and even up to 70\% for those ventilated for more than two days (Tonnelier, Tonnelier et al. 2011). Previous studies have reported the application of various assessments and predictors to increase successful weaning and extubation.

54 Factors associated with extubation failure include age, the primary reason for intubation, neurological dysfunction, cough efficacy, and amount of secretion (Tonnelier, Tonnelier et al. 2011). Extubation failure may also be caused by hidden factors such as delirium (Ely, Shintani et

57 al. 2004) and intensive care unit (ICU)-acquired weakness (Garnacho-Montero, Amaya-Villar et 58 al. 2005). Spontaneous breathing trials (SBTs) are currently the fastest approach to wean patients

60 (MacIntyre, Cook et al. 2001), and it has been reported to be the most accurate predictor of 61 extubation failure (Yang and Tobin 1991). A single daily spontaneous breathing trial lasting 62 from 30 minutes to 2 hours has been recommended as the primary approach to weaning (Cook, 
63 Meade et al. 2000, MacIntyre, Cook et al. 2001). However, the probability of successful

64 extubation in patients with acute respiratory failure may be related to a variety of factors not

65 limited to traditional "weaning parameters", and a clinical composite scoring method is lacking.

66 A possible approach is to assess the preparedness of weaning by using a checklist-based bundle

67 approach, such as the WEANS NOW checklist, which has been recommended to assess the

68 degree of preparedness of a patient to begin breathing spontaneously (Hasani and Grbolar 2008,

69 Witt 2008, Frances 2010, Godara, Hirbe et al. 2014, Johnson and Abraham 2015, Mendez 2018).

70 This evaluation method involves the assessment of eight items. However, the WEANSNOW

71 checklist has not previously been investigated with regards to predicting the success of liberation

72 from MV. Therefore, this study aimed to assess the prognostic ability of a composite score based

73 on the WEANSNOW checklist for extubation failure in intubated and mechanically ventilated

74 patients in a medical intensive care unit.

75

76

\section{Materials \& Methods}

\section{Study design}

79 This retrospective analysis was conducted at the medical ICUs of National Taiwan University

80 Hospital, a university-affiliated medical center in northern Taiwan. The Institutional Research

81 Ethics Committee A of the National Taiwan University Hospital approved this study

82 (\#201808101RINA) and waived the need for informed consent from the patients.

83

\section{Setting}


85 The medical ICUs in this hospital contain a total of 57 beds, with more than $90 \%$ bed occupancy;

86 more than $70 \%$ of the admitted patients are given MV support due to acute respiratory failure. A

87 physician-initiated, protocolized weaning process is used in these ICUs, in which the attending

88 physician, who is a certified intensivist, decides whether the patient's condition is suitable for a

89 progressive reduction in the level of MV support by daily screening for the preparedness of a

90 spontaneous breathing trial. The first weaning trial for an intubated patient is performed when

91 they meet the following criteria: resolution of the disease for which the patient was intubated,

92 cardiovascular stability without or minimal vasopressors, no continuous sedation and adequate

93 oxygenation defined as a $\mathrm{PaO}_{2} / \mathrm{FiO}_{2}$ ratio of at least $150 \mathrm{mmHg}$ with positive end-expiratory

94 pressure of up to $8 \mathrm{cmH}_{2} \mathrm{O}$ (Boles, Bion et al. 2007). The practice of respiratory therapists was to

95 perform physiological assessment and provided the results as 'weaning parameters' to the

96 medical records for most of the patients, whereas the attending intensivist decided to extubate the

97 patients. The ICUs of this study did not mandate the documentation of WEANS NOW

98 assessment on the medical records. Extubation is then performed based on the conventional

99 approach of a successful single daily spontaneous breathing trial lasting from 30 minutes to 2

100 hours. If the trial is unsuccessful, the patient is allowed to rest before another trial is attempted

101 (MacIntyre, Cook et al. 2001). This study focused on patients who underwent extubation based

102 on this standardized weaning protocol. The patients then underwent extubation and liberation

103 from MV, and their general and respiratory status were observed for at least 48 hours. The

104 clinical care team then decided whether the successfully extubated patients could be transferred 105 out of the ICU.

106

107 Participants 
108 We screened the electronic medical records of patients with acute respiratory failure admitted to

109 our medical ICUs from July 2017 to December 2018 for the eligibility of inclusion into this

110 study. Patients who had undergone at least one spontaneous breathing trial followed by

111 extubation were identified and enrolled, including those with documented extubation failure,

112 defined as the need for reintubation with mechanical or noninvasive ventilation or death due to

113 respiratory failure without re-intubation, within two days after extubation (the 'failure' group)

114 (Rothaar and Epstein 2003), and those who were successfully extubated during the same period

115 (the 'success' group). Of the patients with multiple extubation attempts during the same ICU

116 stay, only the first attempt was included for analysis. Patients were excluded if they had at least

117 one of the following conditions: documented endotracheal tube withdrawal and MV as an end-

118 of-life measure, inadvertent removal of the endotracheal tube despite a previous weaning trial,

119 and patients with missing data related to the variables required for analysis.

120

121 Development of the WEANSNOW bundle assessment score

122 The operational definitions of the individual components of the WEANSNOW score (WS) was

123 decided after a discussion among the investigators based on the literature regarding suitability for

124 weaning (Hasani and Grbolar 2008, Witt 2008, Frances 2010, Godara, Hirbe et al. 2014, Johnson

125 and Abraham 2015, Mendez 2018). Eight components were identified: $W$ (weaning profile), $E$

126 (endotracheal tube), $A$ (arterial blood gas analysis), $N$ (nutrition), $S$ (secretions), $N_{2}$

127 (neuromuscular), $O$ (obstruction of the airway), $W_{2}$ (wakefulness). By reviewing the literature, 128 we found a lack of evidence-based generation of the WEANS NOW criteria, despite that this 129 score had appeared in several references. The author decided each criterion for the individual 130 components based on the clinician experience-based consensus among the four investigators of 
131 this study. These components were regarded to be modifiable components to assess the

132 feasibility of testing spontaneous breathing and final extubation. For the Glasgow Coma Score of

133 the 'Wakefulness' item, the verbal component was designated as 5 if the patients could provide a

134 correct response to the assessing nurse through any non-verbal communication. This item was

135 scored as 1 if the patient did not provide any non-verbal response to the assessing nurse, whereas

136 the patient would be scored as 3 if the patient showed a response but not considered correct to

137 the nurse's calling or direction. As this study considered that the concept of 'preparedness'

138 should be given to the criteria, each bundle component was scored 0 if the patient fulfilled the

139 operational definition of the assessment or 1 if they did not. The scores of all eight components

140 were summed for the WS composite score, with a minimum of 0 and a maximum of 8 points.

141 Definitions of the operational criteria are summarized in Table 1. If there were more than one

142 session of clinical and physiological assessment regarding the WEANS NOW components, only

143 the assessment data closest to the time of extubation would be used.

\section{Data collection and data sources}

146 The investigators collected clinical information from the institutional electronic medical record

147 system, including gender, age, admission diagnosis, comorbidities, units, admission APACHE II

148 score, length of MV use, and ICU length of stay. As this study was retrospective, the

149 investigators retrieved the individual information regarding the components of the WS from the 150 electronic medical records.

151

152 Statistical analysis 
153 All statistical analyses were carried out using STATA statistical software (StataCorp LLC,

154 Texas, USA). We first performed a descriptive analysis of the background of the patients.

155 Clinical and demographic characteristics, physiological parameters related to weaning and

156 extubation assessments, components of the WS, and total WSs were compared between the

157 failure and success groups. We then performed multivariate logistic regression analysis,

158 including significant variables in univariate analysis, defined as a p-value of 0.1 or less in the

159 univariate analysis comparing the success and failure groups, to assess the potential factors

160 associated with weaning outcomes.

161 Continuous variables were expressed as mean $+/-\mathrm{SD}$, and categorical variables as

162 number and percentage. Inferential statistics were performed using the chi-square test, Fischer's

163 exact test, and independent t-test. A p-value of $<0.05$ was considered to be statistically

164 significant.

165

166

167 Results

168 Participants

169 Figure 1 shows the flow diagram of the patients included in this study. A total of 289 patients

170 admitted were supported with mechanical ventilation during the study period, and 205 of them

171 underwent at least one attempt of extubation at the ICU, including $138(67.3 \%)$ who succeeded

172 in the first attempt of extubation and $67(32.7 \%)$ who failed. For the failure group, 22 were re-

173 intubated without receiving noninvasive ventilation, whereas 38 received NIV, but 28 were later

174 reintubated, and ten were liberated from NIV upon transferred out the ICU; seven patients died

175 because of withholding reintubation or noninvasive ventilation.

Peer] reviewing PDF | (2019:10:42072:2:0:NEW 4 Mar 2020) 
177 during the study period, including 289 receiving MV. Of these 289 patients, $148(51.2 \%)$ were

178 transferred out of the ICU after successful liberation from MV, 91 (31.5\%) died, and $50(17.3 \%)$

179 were transferred out of the ICU under a ventilator-dependent state.

180 Table 2 compares the demographic and clinical characteristics between the two groups.

181 Compared with the failure group, the success group had a significantly shorter duration of MV

182 before the weaning attempt $(11.2 \pm 11.6$ vs. $31.7 \pm 26.2$ days, $\mathrm{p}<0.001)$, more with congestive heart

183 failure ( $42.0 \%$ vs. $25.4 \%, \mathrm{p}=0.020)$, and had different distribution of the types of acute

184 respiratory failure $(\mathrm{p}=0.037)$ (Table 2$)$.

185

186 Comparisons of physiological parameters and WS

187 Table 3 compares the physiological parameters related to the assessments during the weaning

188 process and WSs between the success and failure groups. Univariate analysis showed significant

189 differences in maximum inspiratory pressure $(\mathrm{p}=0.001)$, maximum expiratory pressure

$190(p=0.005)$, spontaneous tidal volume $(p<0.001)$, respiratory rate $(p<0.001)$, rapid shallow

191 breathing index $(\mathrm{p}<0.001)$, average WS $(\mathrm{p}<0.001)$ and three of the components of the scoring

192 system, including weaning parameters $(\mathrm{p}<0.001)$, neuromuscular $(\mathrm{p}=0.039)$ and wakefulness

$193(p=0.001)$ assessments between the two groups. More patients in the weaning success had both

$194 \mathrm{RSBI}<105$ and $\mathrm{WS}=0$ than those in the failure group $(59.4 \%$ vs. $22.4 \%, \mathrm{p}<0.001)$.

195 The results of multivariate logistic regression analysis for the factors associated with

196 extubation success in the included patients are summarized in Table 4. A WEANS NOW Score $\geq$

$1971(\mathrm{OR}=2.880,95 \% \mathrm{CI}=1.291-6.426, \mathrm{p}=0.010)$ and intubation duration $>21$ days $(\mathrm{OR}=7.752$, 
$19895 \% \mathrm{CI}=3.560-16.879, \mathrm{p}<0.001)$ were independently associated with an increased probability of 199 extubation failure.

200 For sensitivity analysis, we also separated the item 'wakefulness' from the WS score in 201 the multivariate analysis. Logistic regression showed that the "total WS minus the wakefulness 202 score $\geq 1$ ' remained a significant associating factor for extubation failure (OR=3.552, 95\% $203 \mathrm{CI}=1.548-8.150, \mathrm{p}=0.003)$, along with intubation duration $>21$ days $(\mathrm{OR}=7.862,95 \% \mathrm{CI}=3.507$ $204-17.623, \mathrm{p}<0.001)$. In contrast, wakefulness was not independently associated with extubation 205 failure in this study group $(\mathrm{OR}=1.372,95 \% \mathrm{CI}=0.630-2.991, \mathrm{p}=0.426)$ (See Table $1 \mathrm{~S}$ of 206 Supplementary File 2).

207

208

209 Discussion

210 In this study, we developed a composite assessment score for the preparedness of weaning to 211 study its association with the outcomes of weaning in patients with acute respiratory failure 212 receiving MV. The results showed that the composite WS, intended to be used in a 'bundle' 213 score, was associated with weaning success when the score was 0 independently of the 214 commonly used rapid shallow breathing index.

215 Successful extubation is traditionally predicted based on physiological assessments and 216 calculated parameters such as the rapid shallow breathing index (Yang and Tobin 1991). Other 217 prediction models include APACHE II score (Afessa, Hogans et al. 1999), CROP index (Yang 218 and Tobin 1991), relative inspiratory effort (Kline, Zimnicki et al. 1987), alveolar-arterial 219 oxygen tension gradient + blood urea nitrogen + gender score $(A+B+G)($ Scheinhorn, 220 Hassenpflug et al. 1995), new weaning index based on ventilatory endurance and the efficiency 
221 of gas exchange (Jabour, Rabil et al. 1991), and Integrated Weaning Index (Nemer, Barbas et al.

222 2009). Several studies have reported that commonly used weaning indices have suboptimal

223 prediction power for successful liberation from MV (MacIntyre, Cook et al. 2001, Kacmarek,

224 Stoller et al. 2016). These indices are commonly implemented in a clinical setting, are performed

225 by respiratory therapists, and focus more on ventilation function and less on airway condition.

226 Previous reports have suggested that a substantial proportion of patients who fail extubation after

227 a successful spontaneous breathing trial should be defined as "airway failure," especially those

228 who are reintubated within 48 hours after extubation. We also used 48 hours to define extubation

229 success in our analysis. We found that most of the patients who were prepared for extubation had

230 a WS of 0 , suggesting that the clinicians were also confident about the preparedness for

231 extubation. Therefore, we did not perform the receiver operating characteristic curve analysis to

232 compare the accuracy with other weaning indices.

233 We also focused on components other than direct measurements of respiratory

234 mechanics, thereby emphasizing the importance of adequately maintained natural airway

235 function. The effect of an adequately sized artificial airway on the work of breathing is

236 controversial (Straus, Louis et al. 1998). However, endotracheal tubes, which are partially

237 obstructed by airway secretions, may not show abnormal findings by measuring weaning

238 parameters, and may, therefore, also significantly increase the work of breathing after extubation,

239 potentially resulting in airway failure requiring re-intubation. The size of the endotracheal tube

240 can also affect the results of weaning trials. In critically ill patients, a decrease in internal

241 diameter and an increase in minute ventilation increase the work of breathing. Adults have a

242 critical increase in workload when the tube has an internal diameter of less than $7 \mathrm{~mm}$ (Sharar

243 1995). Biofilm buildup on the inside of the endotracheal tube can cause dramatic increases in 
244 airway resistance, especially among infants and children (Mietto, Foley et al. 2014).

245 Furthermore, the presence of upper airway obstructions or laryngeal edema may be detected by a

246 cuff leak test showing diminished gas leak around the endotracheal tube with positive pressure

247 breaths (Wratney and Cheifetz 2007). Arterial gas analysis, nutritional impairment (McClave,

248 Martindale et al. 2009), and neuromuscular impairment are considered to affect ventilation

249 function related to endurance, which may not be recognized by measuring weaning parameters

250 alone. Finally, we found that wakefulness was significantly different between the success and

251 failure groups, suggesting that this component contributes to both airway failure and ventilation

252 failure, ultimately resulting in re-intubation.

253 The WEANSNOW bundle may assist in optimizing the preparedness of weaning-

254 extubation, and the WS may be a useful assessment tool to understand the condition of patients

255 with acute respiratory failure more thoroughly. Although for each component, the majority of

256 patients passed the criterion, our data also showed that only $48 \%$ had a total score of zero.

257 Therefore, we would suggest that a bundled assessment might still be needed to remind the

258 clinician about the risk of extubation failure. All of the clinical conditions related to the

259 individual components of the WS can be improved before weaning-extubation if the patient is at

260 high risk of failure. Multivariate regression analysis (Table 4) showed that the other variables

261 used to predict the success of weaning-extubation, such as comorbidities, the reason for

262 intubation, age, and sex, are non-modifiable, and therefore only serve as predictors. Even though

263 the components of the WS can be improved before attempting extubation, patients who are

264 already intubated with an endotracheal tube with a smaller internal diameter or those with

265 chronic pulmonary and airway diseases such as chronic obstructive pulmonary disease that 
266 reduce the WS may not benefit from the WS assessment. Otherwise, the implementation of this

267 bundle assessment to both predict and guide patient care might be considered.

268 There are several limitations to this study. The author decided each criterion for the

269 individual components based on the clinician experience-based consensus as a lack of evidence-

270 based generation of the WEANS NOW criteria. Although the result of multivariate regression

271 showed the significance of WEANS NOW as a bundled assessment, the individual component

272 might need further evaluation in future studies employing prospective inclusion of a sufficient

273 number of patients of different characteristics and physiologic functions, which is beyond the

274 scope of this retrospective study. Also, as our searching showed, most of the articles describing

275 WEANS NOW appear to based on expert experiences and opinions provided in book chapters as

276 a guide to the process in professional practices regarding ventilator weaning and extubation.

277 Nevertheless, the lack of clinical evidence was also one of our original motivations to analyze

278 the usability of this checklist-based assessment. Further evidence-based evaluation of the

279 practice is necessary. Some patient characteristics were difference between the success and

280 failure groups, such as duration of intubation, congestive heart failure as a comorbidity, and the

281 type of respiratory failure as a reason to intubate. Despite that these characteristics were included

282 in the multi-variate analysis, further prospective randomized studies are needed to address these

283 potential factors, such as stratification of patients with different co-morbidity, duration of

284 intubation, and type of respiratory failure. This study only included intubated patients in the

285 medical ICUs of a single medical center. The patients underwent weaning and extubation mainly

286 based on the decisions of the physician, and the nurses followed standardized nursing care

287 procedures. Our findings may not be generalizable to ICUs that have implemented weaning-

288 extubation processes by respiratory therapists, or those that use similar checklist-based 
289

290

291

292

293

294

295

296

297

298

299

300

301

302

303

304

305

306

307

308

309

310

311

312

assessments and management strategies before proceeding with weaning-extubation. Besides, typical patients treated at the surgical ICU are mechanically ventilated for a brief period after surgery; therefore, the WS needs to be validated in the non-medical population of ICU patients. The design of this study designated those with post-extubation NIV use as failure group (Rothaar and Epstein 2003). Recently, the potential of earlier extubation with immediate respiratory support using noninvasive ventilation has been suggested (Yeung, Couper et al. 2018). As the ICUs in this study did not routinely apply NIV for extubated patients unless there was evidence of worsening respiratory conditions requiring MV support, our study design excluded those patients who required either invasive or non-invasive ventilation within two days after extubation. Our study findings might not be generalized to the ICUs that routinely apply NIV proactively after extubation. However, it would be an interesting question whether or not patients with higher WEANS NOW scores can be successfully extubated with NIV as a step down therapy, and prospective studies are needed. Furthermore, regarding the performance of this ICU, only $51.2 \%$ were transferred out of the ICU after successful liberation from MV. These were medical ICUs that most of the patients have impaired gas exchange rather than merely post-procedural liberation of MV. The practice of physicians may have especially affected our determination of extubation outcomes as we defined successful extubation as unassisted spontaneous breathing maintained for at least 48 hours. Therefore, the contribution of ICU performance to WEANS NOW would also need further investigation. This was a retrospective analysis, and the WS was based on information retrieved from the electronic medical records of the hospital. The information needed to decide whether or not the operational criteria of the WEANSNOW bundle checklist had been fulfilled did not necessarily assure actual optimal preparation in that regard. We included all of the patients who experienced an actual extubation attempt; therefore, the study allowed more than one spontaneous breathing trial before extubation, despite that only the 
313 assessment data closest to the time of extubation would be used. Our inclusion of only those

314 patients who experience extubation would preclude those who did not undergo extubation

315 regardless of the scoring of WEANS NOW. An auditing process may be more suitable for the

316 WS. This study did not include a prospective investigation of predictability using a validation

317 cohort of patients with the same inclusion-exclusion criteria. Physicians based on their clinical

318 judgment made the decisions for extubation and re-intubation; however, their decision on

319 whether or not to extubate may have also been based on clinical judgment related to the

320 WEANSNOW components, and therefore the patients with a high probability of extubation

321 failure may have remained intubated until their clinical condition improved. The post-extubation

322 management may not have been standardized so that the decision to re-intubate may also have

323 been affected by the clinicians. For the understanding of the impact of this pre-extubation

324 practice with bundle checklist such as WEANS NOW, a standardized post-extubation care

325 process till ICU discharge or re-institution of MV might be needed.

\section{Conclusions}

329 In conclusion, assessing the pre-extubation status of intubated patients using the WS might

330 provide valuable insights into extubation failure in patients in a medical ICU for acute

331 respiratory failure. As the individual components can be improved by active management, this

332 bundle-based approach may also provide goals to optimize the patients' condition before

333 extubation to achieve better outcomes regarding liberation from MV. Further prospective studies

334 are warranted to elucidate the practice of assessing weaning preparedness. 


\section{Acknowledgments}

338 Not applicable.

339

340

\section{References}

342 Afessa, B., L. Hogans and R. Murphy (1999). "Predicting 3-day and 7-day outcomes of weaning 343 from mechanical ventilation." Chest 116(2): 456-461.

344 Boles, J.-M., J. Bion, A. Connors, M. Herridge, B. Marsh, C. Melot, R. Pearl, H. Silverman, M.

345 Stanchina and A. Vieillard-Baron (2007). "Weaning from mechanical ventilation." European

346 Respiratory Journal 29(5): 1033-1056.

347 Cook, D., M. Meade, G. Guyatt, L. Griffith and L. Booker (2000). Criteria for weaning from

348 mechanical ventilation, Agency for Healthcare Research and Qualit.

349 Ely, E. W., A. Shintani, B. Truman, T. Speroff, S. M. Gordon, F. E. Harrell Jr, S. K. Inouye, G.

350 R. Bernard and R. S. Dittus (2004). "Delirium as a predictor of mortality in mechanically

351 ventilated patients in the intensive care unit." JAMA 291(14): 1753-1762.

352 Frances, C. (2010). Mechanical Ventilation. Clinical Clerkship in Inpatient Medicine. S. Saint, 353 Wolters Kluwer Health: 160-165.

354 Garnacho-Montero, J., R. Amaya-Villar, J. L. García-Garmendía, J. Madrazo-Osuna and C.

355 Ortiz-Leyba (2005). "Effect of critical illness polyneuropathy on the withdrawal from

356 mechanical ventilation and the length of stay in septic patients." Critical Care Medicine 33(2):

357 349-354.

358 Godara, H., A. Hirbe, M. Nassif, H. Otepka and A. Rosenstock (2014). The Washington Manual 359 of Medical Therapeutics, Lippincott Williams \& Wilkins.

360 Hasani, A. and A. Grbolar (2008). "Principles of weaning from the mechanical ventilation." Acta 361 Informatica Medica 16(2): 83. 
362 Jabour, E. R., D. M. Rabil, J. D. Truwit and D. F. Rochester (1991). "Evaluation of a new

363 weaning index based on ventilatory endurance and the efficiency of gas exchange." Am Rev

364 Respir Dis 144(3 Pt 1): 531-537.

365 Johnson, A. P. and J. Abraham (2015). Monitoring for respiratory dysfunction. Critical Care

366 Nursing. K. J. Booker. Oxford, UK, John Wiley \& Sons, Inc.: 46.

367 Kacmarek, R. M., J. K. Stoller and A. Heuer (2016). Egan's Fundamentals of Respiratory Care-

368 E-Book, Elsevier Health Sciences.

369 Kline, J., G. Zimnicki, D. Antonenko and J. Bander (1987). "The use of calculated relative

370 inspiratory effort as a predictor of outcome in mechanical ventilation weaning trials." Respir

371 Care 32: 870-876.

372 MacIntyre, N. R., D. J. Cook, E. Ely, S. K. Epstein, J. B. Fink and J. Heffner (2001). "Evidence-

373 based guidelines for weaning and discontinuing ventilatory support." Chest 120(6): 375S-395S.

374 McClave, S. A., R. G. Martindale, V. W. Vanek, M. McCarthy, P. Roberts, B. Taylor, J. B.

375 Ochoa, L. Napolitano, G. Cresci and A. B. o. Directors (2009). "Guidelines for the provision and 376 assessment of nutrition support therapy in the adult critically ill patient: Society of Critical Care 377 Medicine (SCCM) and American Society for Parenteral and Enteral Nutrition (ASPEN)."

378 Journal of Parenteral and Enteral Nutrition 33(3): 277-316.

379 Mendez, M. P. (2018). Mechanical Ventilation. The Saint-Chopra Guide to Inpatient Medicine.

380 S. Saint and V. Chopra. Oxford, UK, Oxford University Press.

381 Mietto, C., K. Foley, L. Salerno, J. Oleksak, R. Pinciroli, J. Goverman and L. Berra (2014).

382 "Removal of endotracheal tube obstruction with a secretion clearance device." Respiratory Care

383 59(9): e122-e126.

384 Nemer, S. N., C. S. Barbas, J. B. Caldeira, T. C. Cárias, R. G. Santos, L. C. Almeida, L. M.

385 Azeredo, R. A. Noé, B. S. Guimarães and P. C. Souza (2009). "A new integrative weaning index 386 of discontinuation from mechanical ventilation." Critical Care 13(5): R152.

387 Peñuelas, O., F. Frutos-Vivar, C. Fernández, A. Anzueto, S. K. Epstein, C. Apezteguía, M.

388 González, N. Nin, K. Raymondos and V. Tomicic (2011). "Characteristics and outcomes of

389 ventilated patients according to time to liberation from mechanical ventilation." American

390 Journal of Respiratory Critical Care Medicine 184(4): 430-437.

391 Rothaar, R. C. and S. K. Epstein (2003). "Extubation failure: magnitude of the problem, impact

392 on outcomes, and prevention." Current Opinion in Critical Care 9(1): 59-66.

393 Scheinhorn, D. J., M. Hassenpflug, B. M. Artinian, L. LaBree and J. L. Catlin (1995).

394 "Predictors of weaning after 6 weeks of mechanical ventilation." Chest 107(2): 500-505.

395 Sharar, S. R. (1995). "The effects of artificial airways on airflow and ventilatory mechanics:

396 basic concepts and clinical relevance." Respiratory Care 40(3): 257-262. 
397 Straus, C., B. Louis, D. Isabey, F. LEMAIRE, A. Harf and L. Brochard (1998). "Contribution of 398 the endotracheal tube and the upper airway to breathing workload." American Journal of

399 Respiratory and Critical Care Medicine 157(1): 23-30.

400 Thille, A. W., I. Cortés-Puch and A. Esteban (2013). "Weaning from the ventilator and

401 extubation in ICU." Current Opinion in Critical Care 19(1): 57-64.

402 Tonnelier, A., J.-M. Tonnelier, E. Nowak, C. Gut-Gobert, G. Prat, A. Renault, J.-M. Boles and E.

403 L'Her (2011). "Clinical relevance of classification according to weaning difficulty." Respiratory 404 Care 56(5): 583-590.

405 Witt, C. A. (2008). Weaning of Mechanical Ventilation. The Washington Manual of Critical

406 Care. M. H. Kollef, T. J. Bedient and W. Isakow, Lippincott Williams \& Wilkins: 101-103.

407 Wratney, A. T. and I. M. Cheifetz (2007). "AARC clinical practice guideline-Removal of the 408 endotracheal tube-2007 Revision \& Update." Respiratory Care 52(1): 81-93.

409 Yang, K. L. and M. Tobin (1991). "A prospective study of indexes predicting the outcome of 410 trials of weaning from mechanical ventilation." New England Journal of Medicine 324(21):

411 1445-1450.

412 Yeung, J., K. Couper, E. G. Ryan, S. Gates, N. Hart and G. D. Perkins (2018). "Non-invasive 413 ventilation as a strategy for weaning from invasive mechanical ventilation: a systematic review 414 and Bayesian meta-analysis." Intensive Care Medicine 12: 1-13. 


\section{Table 1 (on next page)}

Components of the proposed WEANSNOW bundle evaluation. 


\section{Table 1. Components of the proposed WEANSNOW bundle evaluation}

\begin{tabular}{|l|l|l|}
\hline Acronym & Component & Description* \\
\hline$W$ & Weaning profile & $\begin{array}{l}\text { Pre-extubation physiological profile meets all of the following } \\
\text { criteria: } \mathrm{MIP}=-30 \mathrm{~cm}_{2} \mathrm{O} \text { or better; } \mathrm{MEP}=+30 \mathrm{~cm}_{2} \mathrm{O} \text { or } \\
\text { better; spontaneous } \mathrm{V}_{\mathrm{T}} \geq 5 \mathrm{ml} / \mathrm{IBW} / \mathrm{kg} ; \text { spontaneous } \mathrm{V}_{\mathrm{E}} \leq 10 \\
\mathrm{~L} / \mathrm{m} ; \mathrm{RSBI}<105 \text { breaths } / \mathrm{min} / \mathrm{L}\end{array}$ \\
\hline$E$ & Endotracheal tube & Endotracheal tube with internal diameter $\geq 7.0 \mathrm{~mm}$ \\
\hline$A$ & Arterial blood gas data & $\mathrm{P}_{\mathrm{a}} \mathrm{O}_{2} \geq 60 \mathrm{mmHg} ;$ no metabolic alkalosis \\
\hline$N_{2}$ & Nutrition & Albumin $\geq 3.0$ gm/dl; no electrolyte derangement \\
\hline$S$ & Secretion & Airway suctioning $\leq 1$ session per hour \\
\hline$N$ & Neuromuscular condition & Not under neuromuscular depressing medications \\
\hline$O$ & Obstruction of main airways & $\begin{array}{l}\text { Clinical absence of airway obstruction, assessed by breathing } \\
\text { sounds, chest radiography, ventilator display, and cuff deflation } \\
\text { leak percentage } \geq 15.5 \%\end{array}$ \\
\hline$W_{2}$ & Wakefulness & \begin{tabular}{l} 
Glasgow Coma Scale $\geq 12$ \\
\hline
\end{tabular} \\
\hline
\end{tabular}

3 *MIP: maximum inspiratory pressure; MEP: maximum expiratory pressure; $\mathrm{V}_{\mathrm{T}}$ : tidal volume; $\mathrm{V}_{\mathrm{E}}$ : minute 4 ventilation; RSBI: rapid shallow breathing index. 


\section{Table 2 (on next page)}

Comparisons of demographic and clinical characteristics of the patients with successful and failed weaning attempts. 
1 Table 2. Comparisons of demographic and clinical characteristics of the patients with

2 successful and failed weaning attempts

\begin{tabular}{|c|c|c|c|c|}
\hline Variable & $\begin{array}{l}\text { Total patients } \\
(\mathrm{n}=205)\end{array}$ & $\begin{array}{l}\text { Weaning success } \\
(\mathrm{n}=138)\end{array}$ & $\begin{array}{l}\text { Weaning failure } \\
(\mathrm{n}=67)\end{array}$ & $\mathrm{p}$-value \\
\hline Age, years & $68.5 \pm 14.0(24-97)$ & $68.1 \pm 13.7(34-93)$ & $69.1 \pm 14.8(24-97)$ & 0.637 \\
\hline Male, n (\%) & $124(60.5 \%)$ & $85(61.6 \%)$ & $39(58.2 \%)$ & 0.642 \\
\hline Duration of intubation, days & $17.9 \pm 20.1(2-108)$ & $11.2 \pm 11.6(2-67)$ & $31.7 \pm 26.2(2-108)$ & $<0.001$ \\
\hline \multicolumn{5}{|l|}{ Main comorbidity, n (\%) } \\
\hline Congestive heart failure & $75(36.6 \%)$ & $58(42.0 \%)$ & $17(25.4 \%)$ & 0.020 \\
\hline $\begin{array}{l}\text { Chronic obstructive pulmonary } \\
\text { disease }\end{array}$ & $43(21.0 \%)$ & $28(20.3 \%)$ & $15(22.4 \%)$ & 0.729 \\
\hline Chronic kidney disease & $69(33.7 \%)$ & $45(32.6 \%)$ & $24(35.8 \%)$ & 0.648 \\
\hline Hypertension & $95(46.3 \%)$ & $65(47.1 \%)$ & $30(44.8 \%)$ & 0.754 \\
\hline Diabetes & $52(25.4 \%)$ & $35(25.4 \%)$ & $17(25.4 \%)$ & 0.999 \\
\hline Malignancy & $92(44.9 \%)$ & $57(41.3 \%)$ & $35(52.2 \%)$ & 0.140 \\
\hline \multicolumn{5}{|l|}{ Type of respiratory failure, $\mathrm{n}(\%)$} \\
\hline Type I & $57(27.8 \%)$ & $41(29.7 \%)$ & $16(23.9 \%)$ & 0.037 \\
\hline Type II & $86(42.0 \%)$ & $64(46.4 \%)$ & $22(32.8 \%)$ & \\
\hline Type III & $9(4.4 \%)$ & $4(2.9 \%)$ & $5(7.5 \%)$ & \\
\hline Type IV & $53(25.9 \%)$ & $29(21.0 \%)$ & $24(35.8 \%)$ & \\
\hline APACHE II score on admission & $21.3 \pm 8.1$ & $21.4 \pm 8.1$ & $21.1 \pm 8.1$ & 0.860 \\
\hline
\end{tabular}

4 APACHE: acute physiology and chronic health evaluation 


\section{Table $\mathbf{3}$ (on next page)}

Comparison of physiological parameters and WEANSNOW score 
1 Table 3. Comparison of physiological parameters and WEANSNOW score

\begin{tabular}{|c|c|c|c|c|}
\hline Variable & $\begin{array}{l}\text { Total patients } \\
(\mathrm{n}=205)\end{array}$ & $\begin{array}{l}\text { Weaning success } \\
(n=138)\end{array}$ & $\begin{array}{l}\text { Weaning failure } \\
(\mathrm{n}=67)\end{array}$ & p-value \\
\hline $\mathrm{MIP}, \mathrm{cmH}_{2} \mathrm{O}$ & $-37.1 \pm 11.4$ & $-38.9 \pm 11.1$ & $-33.4 \pm 11.2$ & 0.001 \\
\hline $\mathrm{MEP}, \mathrm{cmH}_{2} \mathrm{O}$ & $43.4 \pm 16.8$ & $45.7 \pm 16.9$ & $38.7 \pm 15.6$ & 0.005 \\
\hline $\mathrm{V}_{\mathrm{T}}, \mathrm{mL}$ & $395.4 \pm 150.0$ & $429.2 \pm 150.8$ & $325.9 \pm 122.8$ & $<0.001$ \\
\hline $\mathrm{V}_{\mathrm{E}}, \mathrm{L} / \mathrm{min}$ & $8.3 \pm 3.2$ & $8.4 \pm 2.8$ & $8.1 \pm 3.7$ & 0.567 \\
\hline RR & $21.7 \pm 6.5$ & $20.3 \pm 6.0$ & $24.7 \pm 6.5$ & $<0.001$ \\
\hline RSBI & $68.3 \pm 49.4$ & $56.3 \pm 35.1$ & $93.9 \pm 63.8$ & $<0.001$ \\
\hline \multicolumn{5}{|l|}{ WEANSNOW component } \\
\hline$W$ eaning profile, passed & $148(72.2 \%)$ & $114(82.6 \%)$ & $33(49.3 \%)$ & $<0.001$ \\
\hline Endotracheal tube, passed & $201(98.0 \%)$ & $137(99.3 \%)$ & $64(95.5 \%)$ & 0.103 \\
\hline Arterial blood gas analysis, passed & $205(100 \%)$ & $138(100 \%)$ & $67(100 \%)$ & 1.000 \\
\hline Nutrition, passed & $201(98.0 \%)$ & $135(97.8 \%)$ & $66(98.5 \%)$ & 1.000 \\
\hline Secretions, passed & $194(94.6 \%)$ & $130(94.2 \%)$ & $64(95.5 \%)$ & 0.758 \\
\hline Neuromuscular, passed & $198(96.6 \%)$ & $136(98.6 \%)$ & $62(92.5 \%)$ & 0.039 \\
\hline Obstruction of the airway, passed & $198(96.6 \%)$ & $135(97.8 \%)$ & $63(94.0 \%)$ & 0.219 \\
\hline Wakefulness, passed & $137(66.8 \%)$ & $103(74.6 \%)$ & $33(49.3 \%)$ & 0.001 \\
\hline WEANSNOW score, average & $0.75 \pm 0.83$ & $0.51 \pm 0.71$ & $1.22 \pm 0.85$ & $<0.001$ \\
\hline \multicolumn{5}{|l|}{ WEANSNOW score } \\
\hline 0 & $98(47.8 \%)$ & $83(60.1 \%)$ & $15(22.4 \%)$ & $<0.001$ \\
\hline$\geq 1$ & $107(52.2 \%)$ & $57(40.7 \%)$ & $50(76.9 \%)$ & \\
\hline RSBI $<105$ and WEANSNOW score $=0$ & $97(47.3 \%)$ & $82(59.4)$ & $15(22.4 \%)$ & $<0.001$ \\
\hline
\end{tabular}

2 
3 MIP: maximum inspiratory pressure; MEP: maximum expiratory pressure; $\mathrm{V}_{\mathrm{T}}$ : tidal volume; $\mathrm{V}_{\mathrm{E}}$ : minute ventilation;

4 RR: respiratory rate; RSBI: rapid shallow breathing index 


\section{Table 4 (on next page)}

Multivariate logistic regression analysis of the factors and variables associated with weaning success. 
1 Table 4 Multivariate logistic regression analysis of the factors and variables associated with

2 extubation failure

3

\begin{tabular}{|l|l|l|l|r|}
\hline Variable & $\mathrm{N}(\%)$ & OR & $95 \% \mathrm{CI}$ & $\mathrm{p}$-value \\
\hline Heart failure & $75(36.6 \%)$ & 0.609 & $0.276-1.344$ & 0.219 \\
\hline Type 1 or Type 2 respiratory failure & $143(69.8 \%)$ & 0.533 & $0.252-1.128$ & 0.100 \\
\hline Intubation days $>21$ & $53(25.9 \%)$ & 7.752 & $3.560-16.879$ & $<0.001$ \\
\hline $\mathrm{MIP} \leq-20 \mathrm{cmH}_{2} \mathrm{O}$ & $189(92.2 \%)$ & 0.559 & $0.143-2.189$ & 0.403 \\
\hline $\mathrm{MEP} \geq 30 \mathrm{cmH}_{2} \mathrm{O}$ & $157(76.6 \%)$ & 0.996 & $0.405-2.449$ & 0.993 \\
\hline $\mathrm{RSBI}<105$ & $26(13.3 \%)$ & 0.390 & $0.135-1.126$ & 0.082 \\
\hline WEANS NOW score $\geq 1$ & $107(52.2 \%)$ & 2.880 & $1.291-6.426$ & 0.010 \\
\hline
\end{tabular}

4

5 MIP: maximum inspiratory pressure; MEP: maximum expiratory pressure; RSBI: rapid shallow breathing index;

6 OR: odds ratio; CI: confidence interval 
Figure 1

Flow diagram of the patients included in this study.

Detailed statement of the numebers of inclusion and exclusion for this study.

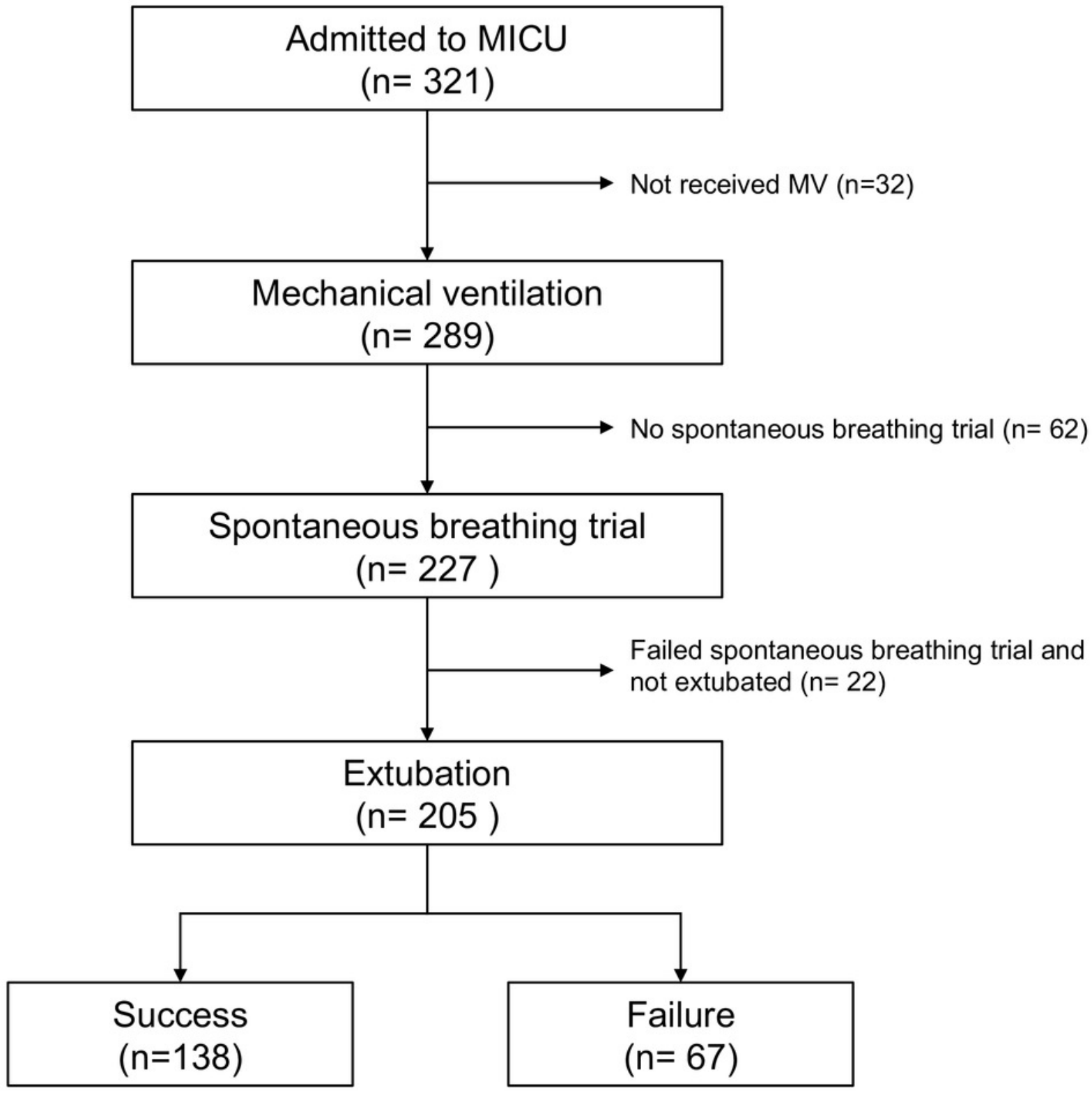

